\title{
Effects of Icon Design \& Styles On Human-Mobile Interaction: Case Study on e-Literate vs. Non e-Literate user
}

Zulfiqar A. Memon ${ }^{1}$, Rakhi Batra ${ }^{2}$, Jawaid A. Siddiqi ${ }^{2}$, Javed A. Shahani ${ }^{2}$

\begin{abstract}
Cell phones have turned out to be the most central communication gadget in our daily life. This results in an enormously intense competition between almost all the mobile phone vendors. Despite manufacturer's diverse types of advertising strategies such as exceptional price cut offers or modern attractive functions, what really matters is whether this everyday communication gadget has been designed according to the preference and requirements of all types of users. The miniature type screen interface design is one of the recent research themes of the Human-Computer Interaction domain. Because of the restricted screen size, "icons" have been considered as the prevailing style in the functional course of action of a cell phone. This article investigates the effects of icon designs and styles employed by different vendors on the perception of both the e-literate users and non e-literate users. We have explored various articles from the literature, summarizing their results of experimental validations, and a comparative analysis is described at the end. It was found that designers of mobile phone icons have to balance a trade-off between the need, requirements and understanding of both e-literate and non e-literate users.
\end{abstract}

Keywords: Mobile phones, Icon designing, Human-mobile interaction.

\section{Introduction}

With the enhancement of technology, the communication devices like mobile phones are not limited to common applications of calling and texting, they provide much more facilities now than ever before. These applications are represented through icons at the interface of small screen of mobile phones and smart phones to facilitate users to perform their everyday jobs. Visual facets, such as graphics display on the screen and icons, are fundamental rudiments of human-mobile interaction; they have been used in interface design in broader sense on the supposition that visual icons are adequate for handling impediments like language and present information in summarized form.

Literature has abundant evidence of analyzing the graphic illustrations by using icons for portable devices. Investigating the level that any icon symbolizes the sense of the purpose for which it has been intended to design, selected and configured by the cell phone maker and designer, has attracted the researcher community at large. A large proportion of older adults (the non e-literate users) due to their aging, grow worse in many of their natural abilities, like perception, motor and abilities being or relating to or involving cognition, which limit the quality of moving freely and their independence, and hence requiring more support [1]. Cell phones can support non e-literate adults for staying connected online; remembering important information by the help of memory aids and portable games stimulates mental exercises and can even provide them fun [2]. However, as being non e-literate they have find these devices more difficult to use and slower to adopt mobile computer technologies. The reluctance of these non e-literate users to adopt mobile devices can be explained by the modern $\mathrm{HCI}$ investigations that has inspected various diverse usability issues [3], [4].

On the other hand, the situation from the perspective of younger users (e-literate users)

\footnotetext{
${ }^{1}$ Department of Computer Science, National University of Computer and Emerging Sciences, Karachi

${ }^{2}$ Department of Computer Science, Sukkur IBA University

Corresponding email: zulfiqar.memon@nu.edu.pk
} 
is quite opposite. They are very enthusiastic and motivated to use these mobile devices for almost all tasks of their daily life. And, as they don't share any of the disabilities like the older users mentioned above, they interact with these mobile devices in a quite easy way and in a fast pace.

The literature has evidence a very scarce work related to the investigations of the effect of icons made up of graphics on e-literate as well as on non e-literate user's use of portable equipment, even though the icons have a profound impact on most interfaces of the user cell phones. The ability of adults who are too aged to interpret icons made up of graphics, is effected by the gradual weakening in cognitive as well as perceptual abilities complemented with gradual decline in the age. The strength of interpreting the icons in older non e-literate users has also been affected by their low and narrow interaction with present-day smart equipment coupled with the low familiarity with the icons of the device and its various apps.

This article discusses that in order for none-literate users to be able to use the interfaces and icons many icons need to be redesigned. Below, in Section 2, various articles have been explored from the literature, summarizing their results of experimental validations and a comparative analysis is explained in Section 3. At the end, Section 4 concludes that a trade-off among the need, requirements and understanding of both e-literate and non eliterate users must be balanced by the designers of the icons of the smart phones.

\section{Case Studies}

Literature have evidenced much promising work on designing computer interfaces for non e-literate users (e.g. [5], [6], [7]), but less work has appeared specifically at the usability of computer icons. The literature has identified that many of the characteristics related to users have affected the usability of computer technology also affect the usability of icons for the group of non e-literate users. These user characteristics include attention, the capacity to learn and remember new information and associations, verbal and visual abilities. In addition to above, the icon usability may also be affected due to less experience with software interfaces by this age group.

The authors in [8] suggest a concrete icon design methodology for mobile base interface for the naïve low literate user segment. They also try to identify the key constructs under cognitive absorption which may have significant effect on behavioral intentions of low literate users. The authors revealed the relationships that exist between icon characteristics, and different dimensions come under cognitive absorption. The author has advocated for metaphor driven icon design methodology for designing icon design interface for the low literate target. As practical contribution, they offer clear design strategies for crafting coherent sequence effective user interactions which will facilitate self-initiated learning and usage of mobile base application.

In [9], guided by the two major goals the authors have conducted a research. To determine icons characteristics in the sector of mobile phone that ensures high semantic transparency was the first goal. The aim of this goal was to scrutinize Icons' visual complexity and concreteness. They also try to identify the key constructs under cognitive absorption which may have significant effect on behavioral intentions of low literate users. The authors revealed the relationships that exist between icon characteristics and different dimensions come under cognitive absorption [7, 10]. The author has advocated for metaphor driven icon design methodology for designing icon design interface for the low literate target. As practical contribution they offer clear design strategies for crafting coherent sequence effective user interactions which will facilitate self-initiated learning and usage of mobile base application. To determine icons characteristics in the sector of mobile phone that ensures high semantic transparency was the first goal. The aim of this goal was to scrutinize Icons' visual complexity and concreteness. 
It is suggested in [11], that as far as the established functions/objects are concerned, such as messaging, address book, calls log, mobile internet etc., the icons of the smart phone, in relation to different age groups, have been standardized or customized. As for as safety applications [12] are concerned, high motivation has been evidenced however, to standardize the icons of the smart phone as compared to other applications. High performance variation across handsets of different sorts will be experienced by the users, if standardization will not be achieved in the icons of mobile phones. The designers of the icons must make them as learnable as well as understandable as possible, if in case the standardization is not feasible as indicated in the literature. For such popular device for interaction such as mobile phone, the performance could be problematic in absolute terms as such indicated in the literature. As for as safety applications [12] are concerned, high motivation has been evidenced however, to standardize the icons of the smart phone as compared to other applications. High performance variation across handsets of different sorts will be experienced by the users, if standardization will not be achieved in the icons of mobile phones. The designers of the icons must make them as learnable as well as understandable as possible if the standardization is not feasible as indicated in the literature. For such popular device for interaction such as mobile phone, the performance could be problematic in absolute terms as indicated in the literature. Therefore, for further evaluations of alternatives and for redesigning purposes, "calls log" is seemingly a good candidate. Just to mention, that this is actually the main objective and holds true irrespective of any group of age, and was holding the main scope of their study.

As far as safety applications [13] are concerned, high motivation has been evidenced however, to standardize the icons of the smart phone as compared to other applications. High performance variation across handsets of different sorts will be experienced by the users, if standardization will not be achieved in the icons of mobile phones. The designers of the icons must make them as learnable as well as understandable as possible, if in case the standardization is not feasible as indicated in the literature. For such popular device for interaction such as mobile phone, the performance could be problematic in absolute terms as such indicated in the literature. The authors included 54 icons in their study and their results related to functions suggest 6 advices for future research on the workings of icons and icon design practices:

- As far as safety applications are concerned, high motivation has been evidenced however, to standardize the icons of the smart phone as compared to other applications.

- High performance variation across handsets of different sorts will be experienced by the users, if standardization will not be achieved in the icons of mobile phones.

- The designers of the icons must make them as learnable as well as understandable as possible, if in case the standardization is not feasible as indicated in the literature.

- For such popular device for interaction such as mobile phone, the performance could be problematic in absolute terms as such indicated in the literature.

- The users frequently interpreted correctly the Icons with concrete imagery.

The authors in [14] have shown that despite widespread use and acceptance in diverse computing environments, there are still several issues in the design of icons. They have found that there are significant differences in the performance of different offerings. In particular, the authors have found that:

- As far as safety applications are concerned, high motivation has been evidenced however, to standardize the icons of the smart phone as compared to other applications. 
- High performance variation across handsets of different sorts will be experienced by the users, if standardization will not be achieved in the icons of mobile phones.

- The designers of the icons must make them as learnable as well as understandable as possible, if in case the standardization is not feasible as indicated in the literature.

- For such popular device for interaction such as mobile phone, the performance could be problematic in absolute terms as such indicated in the literature.

- The users frequently interpreted correctly the Icons with concrete imagery.

In [15], the authors after conducting an empirical experiment claim that not all of the cell phone users could identify an alarm clock, despite the fact that they are using on daily basis the phones they possess. Many of them replied, when asked further, that for them the mobile phone is used mainly for sending messages and receiving or making calls. As far as safety applications [16] are concerned, high motivation has been evidenced however, to standardize the icons of the smart phone as compared to other applications. High performance variation across handsets of different sorts will be experienced by the users, if standardization will not be achieved in the icons of mobile phones. The designers of the icons must make them as learnable as well as understandable as possible, if in case the standardization is not feasible as indicated in the literature. For such popular device for interaction such as mobile phone, the performance could be problematic in absolute terms as such indicated in the literature.

\section{Comparison and Conclusion}

Some researchers identify more categories than others; however, in general, many researchers employ similar principles to classify icons. Due to researcher's inclusion criteria some differences also exist. Due to its text element, some authors would consider exemplar to the icon depicting a knife \& fork for 'restaurant' and the icon depicting a rubbish bin for 'trash' would most likely be considered a mixed icon by few authors. Some authors have found a recognition rate of more than $66.7 \%$, whereas others found below $40 \%$. Literature has also evidenced, among age groups, many prominent differences in recognition rates; the recognition rate displayed by males being only $4 \%$ higher than that displayed by females; there is no significant difference between genders; and with recognition rate decreasing as age increases. We have concluded and presented a number of reasons why interface usability and good icon is particularly important on mobile devices used by this population. We have also concluded that in order for non e-literate users to be able to use the interfaces and icons many icons need to be redesigned. Based on our results, we suggest that icons incorporate commonly used symbols or concrete objects. Significantly, we suggest, using familiar metaphors, reducing semantic distance by choosing icon objects semantically close to the icon meaning, allowing users to choose an icon from a set of potentially suitable icons and using labels. Our empirical results are consistent with many existing icon design guidelines. Nevertheless to improve a non eliterate user's initial usability of icons on mobile devices and other computer interfaces, our results highlight related guidelines that should be followed. Future and existing mobile devices offer non e-literate users diverse and rich opportunities to increase their independence, get connected and to remain active. We expect that by making mobile device icons easier for non e-literate users will have a better chance of being adopted and to use the overall device will be more usable.

\section{REFERENCES}

[1] Goodman, J., Brewster, S., and Gray, P., 2004. Older people, mobile devices and navigation. In: J. Goodman and S. Brewster, eds. HCI and the older population, workshop at the HCI 2004, Leeds,UK, 13-14. Available from: http ://www.dcs.gla.ac.uk/ stephen/ research/utopia/ workshop/goodman.pdf

[2] Inglis, E.A.,et al., $2003 . \quad$ Issues surrounding the user-centred development of a new interactive 
memory aid. Universal Access in the Information Society, 2 (3), 226-234.

[3] Jacko, J.A.,et al., 2002. Macular degeneration and visual icon use: deriving guidelines for improved access. Universal Access in the Information Society, 1 (3), 197-206.

[4] Ziefle, M. and Bay, S., 2005. How older adults meet complexity: aging effects on the usability of different mobile phones. Behaviour \& Information Technology, 24(5), 375-389.

[5] Docampo Rama, M., de Ridder, H., and Bouma, H., 2001. Technology generation and age in using layered user interfaces. Gerontechnology, 1 (1), 25-40.

[6] Gregor, P., Newell, A.F., and Zajicek, M., 2002. Designing for dynamic diversity: interfaces for older people. In: Proceedings of the fifth international ACM conference on assistive technologies (ASSETS), 8-10 July 2002, Edinburgh, Scotland. New York: ACM Press, 151-156.

[7] Fisk, A.D., et al., 2004. Designing for older adults: principles and creative human factors. London: CRC Press.

[8] Sengupta, Avijit and Chang, Klarissa Ting Ting, "Effect of Icon Styles on Cognitive Absorption and Behavioral Intention of Low Literate Users" (2013). PACIS 2013 Proceedings. Paper 184. http://aisel.aisnet.org/pacis2013/184

[9] Sabine Schroder, Martina, "Effects of Icon Concreteness and Complexity on Semantic Transparency: Young vs. Older Users, In: K. Miesenberger et al. (Eds.):
Proceedings of $11^{\text {th }}$ International Conference, ICCHP 2008, LNCS 5105, pp. 90-97, 2008.

[10] Park, D., Schwarz, N.: Cognitive Aging. Buchanan, Philadelphia (1999)

[11] Charalambos Koutsourelakis, Konstantinos Chorianopoulos, "Icons in mobile phones: Comprehensibility differences between older and younger users", In: Information Design Journal, 2010, ca. 100, pp. 22-35, 2010.

[12] Hancock, H. E., Rogers, W. A., Schroeder, D., \& Fisk, A. D. (2004). Safety symbol comprehension: Efects of symbol type, familiarity, and age. Human Factors, 46, 183-195.

[13] C. Gatsou, A. Politis and D. Zevgolis, "The Importance of Mobile Interface Icons on User Interaction", IJCSA, vol. 9, no. 3, 2012, pp. 92-107.

[14] Koutsourelakis, C. \& Chorianopoulos, K., In: The Design Journal, vol. 13, no. 3, 2010, pp. 313-328, 2010.

[15] Restyandito, Chan, Alan H. S., Mahastama, Aditya W., Saptadi, Tri S., "Designing usable icons for non e-literate user", In: The Proceedings of the International MultiConference of Engineers and Computer Scientists 2013 Vol II, IMECS 2013.

[16] Z. Lalji, and J. Good, "Designing new technologies for illiterate populations: A study in mobile phone interface design" in Interacting with Computers, Vol.20, Issue 6, December 2008, Elsevier B.V, 2008. pp. 574-586. 